\title{
Dietary and lifestyle quality indices with/without physical activity and markers of insulin resistance in European adolescents: the HELENA study
}

David Jiménez-Pavón ${ }^{1 *}+$, Maria A. Sesé ${ }^{1}$, Inge Huybrechts ${ }^{2}$, Magdalena Cuenca-García ${ }^{3}$, Gonzalo Palacios ${ }^{4}$, Jonatan R. Ruiz ${ }^{5}$, Christina Breidenassel ${ }^{6}$, Catherine Leclercq ${ }^{7}$, Laurent Beghin ${ }^{8}$, Maria Plada ${ }^{9}$, Yannis Manios ${ }^{10}$, Odysseas Androutsos ${ }^{10}$, Jean Dallongeville ${ }^{11}$, Anthony Kafatos ${ }^{9}$, Kurt Widhalm $^{12}$, Dénes Molnar ${ }^{13}$ and Luis A. Moreno ${ }^{1}$

${ }^{1}$ GENUD (Growth, Exercise, Nutrition and Development) Research Group, Department of Physiotherapy and Nursing,

Faculty of Health Sciences, University of Zaragoza, Avenida Domingo Miral s/n, CP, 50009 Zaragoza, Spain

${ }^{2}$ International Agency for Research on Cancer, Dietary Exposure Assessment Group, 150 Cours Albert Thomas, 69372,

Lyon CEDEX 08, France

${ }^{3}$ Department of Medical Physiology, School of Medicine, University of Granada, Spain

${ }^{4}$ ImFINE Research Group, Department of Health and Human Performance, Facultad de Ciencias de la Actividad Física y del

Deporte (INEF), Universidad Politécnica de Madrid, Madrid, Spain

${ }^{5}$ Department of Physical Education and Sport, School of Sport Sciences, University of Granada, Spain

${ }^{6}$ Institut für Ernährungs- und Lebensmittelwissenschaften-Humanernährung, Rheinische Friedrich-Wilhelms Universität,

Bonn, Germany

${ }^{7}$ National Research Institute on Food and Nutrition, Rome, Italy

${ }^{8}$ Inserm U995, Faculté de médecine, Université Lille 2, Lille, France

${ }^{9}$ Preventive Medicine and Nutrition Clinic, University of Crete, Heraklion, Greece

${ }^{10}$ Department of Nutrition and Dietetics, Harokopio University, Athens, Greece

${ }^{11}$ Research Institute of Child Nutrition Dortmund, Dortmund, Germany

${ }^{12}$ Division of Clinical Nutrition and Prevention, Department of Pediatrics, Medical University of Vienna, Vienna, Austria

${ }^{13}$ Department of Pediatrics, University of Pécs, Pécs, Hungary

(Submitted 2 November 2012 - Final revision received 14 March 2013 - Accepted 15 March 2013 - First published online 19 April 2013)

\section{Abstract}

Emerging data indicate that higher levels of insulin resistance (IR) are common among children and adolescents and are related to cardiometabolic risk; therefore, IR requires consideration early in life. In addition, there is a lack of conclusive evidence regarding the role of dietary nutrients on IR. The Healthy Lifestyle in Europe by Nutrition in Adolescence Cross-Sectional Study (HELENA-CSS) was conducted in European adolescents aged $12.5-17.5$ years. A total of 637 participants with valid homeostasis model assessment (HOMA) index data and who completed at least a $2 \mathrm{~d} 24 \mathrm{~h}$ dietary recall were included in the study ( $60 \%$ of the total HELENA-CSS sample). There were two dietary indices calculated, with the only difference between them being the inclusion or not of physical activity (PA). Markers of IR such as HOMA and the quantitative insulin sensitivity check index (QUICKI) were calculated. Pubertal status, BMI and cardiorespiratory fitness (CRF) were measured as potential confounders. The dietary index including PA was inversely associated with HOMA and directly with the QUICKI in females, but not in males, after adjusting for pubertal status, centre, BMI and CRF. In conclusion, the present study indicates that considering PA as part of the dietary index is of relevance as the resulted index is inversely related to IR independently of potential confounders including CRF. Overall, these findings suggest that intervention studies aimed at preventing IR in young people should focus on increasing the quality of the diet and also on including an optimal PA level in healthy adolescents.

Key words: Diet quality index: Adolescents: Physical activity: Insulin resistance

Abbreviations: CRF, cardiorespiratory fitness; DQI, diet quality index; DQI-A, dietary quality index for adolescents; DQIPA, dietary quality index including physical activity; HELENA, Healthy Lifestyle in Europe by Nutrition in Adolescence; HELENA-CSS, Healthy Lifestyle in Europe by Nutrition in Adolescence Cross-Sectional Study; HOMA, homeostasis model assessment; IR, insulin resistance; PA, physical activity; QUICKI, quantitative insulin sensitivity check index.

*Corresponding author: Dr D. Jiménez-Pavón, email davidj@unizar.es

† Both authors contributed equally to this work. 
Emerging data indicate that higher levels of insulin resistance (IR) are common among children and adolescents and are related to cardiometabolic risk; therefore, IR requires consideration early in life ${ }^{(1)}$. In addition, there is a lack of conclusive evidence regarding the role of dietary nutrients on $\mathrm{IR}^{(2)}$. However, higher physical activity (PA) levels are consistently associated with an improved metabolic profile and a reduced risk for IR in children and adolescents $(<18 \text { years })^{(3-5)}$.

Recent studies have analysed the relationship of different dietary factors with IR in children and adolescents ${ }^{(6-10)}$. These dietary factors include the consumption of sugarsweetened beverages ${ }^{(7,8)}$, PUFA $^{(9)}$ or dietary pattern ${ }^{(6,10)}$. However, the relevant use of dietary indices to assess a compendium of different aspects of the diet (such as quality) in relation to several outcomes has been highlighted in a recent review ${ }^{(11)}$. They conclude that few studies on indexhealth associations have been performed, and most analyses have insufficiently adjusted for potential confounders. Thus, the necessity for further research in order to develop the utility of dietary indices has been stated ${ }^{(11)}$.

Only two studies have focused on the association between diet quality and $\mathrm{IR}^{(12,13)}$. In a study performed in Cretan children and adolescents, it was observed that the presence of three or more factors of the metabolic syndrome was strongly associated with a poor Healthy Eating Index and a low physical fitness, as well as overweight ${ }^{(12)}$. Moreover, Manios et al. ${ }^{(13)}$ proposed a Healthy Lifestyle-Diet Index in a sample of 729 school children from Greece aged 10-12 years that included PA. These authors have observed that adolescents with a lower Healthy Lifestyle-Diet index score were at increased probability for IR.

PA has been shown to be inversely associated with the markers of IR in adolescents ${ }^{(3,4,14,15)}$. Although dietary and PA interventions have been suggested as the ideal approach for the treatment of $\mathrm{IR}^{(16)}$, it would be of interest to study the independent and combined associations of these factors with IR, also taking into consideration sex-specific information. To our knowledge, there are no studies examining the associations of the dietary quality index including PA with the markers of IR in a large cohort of European adolescents. The purpose of the present study was to examine the association of several dietary quality indices, with and without $\mathrm{PA}$, in relation to the markers of IR after controlling for potential confounders.

\section{Methods}

The Healthy Lifestyle in Europe by Nutrition in Adolescence Cross-Sectional Study (HELENA-CSS) is a school-based, multi-centre study, designed to obtain reliable and valid data on nutrition- and health-related factors in adolescents aged $12.5-17.5$ years in ten European cities from nine countries ${ }^{(17)}$. Further details of the methodology of the study have been described elsewhere ${ }^{(18)}$. The total sample of the HELENACSS was 3546 adolescents with a subset of 1089 with blood samples. Only nine centres have been included in the present study because incomplete information was obtained for $24 \mathrm{~h}$ dietary recall analyses from Heraklion. Participants with valid homeostasis model assessment (HOMA) index data and who completed the $24 \mathrm{~h}$ dietary recall for at least $2 \mathrm{~d}$ were included in the study. Based on these criteria, a total of 637 adolescents ( $60 \%$ of the total HELENA study sample) were finally included in the study. Adolescents from this subsample of the HELENA-CSS included in the analyses did not differ from those excluded in the following variables: age; sex; weight; height; HELENA-DIAT (Dietary Assessment Tool) (all $P>0 \cdot 2$ ). The study was performed following the ethical guidelines of the Declaration of Helsinki (1964) (revision of Edinburgh 2000), the Good Clinical Practice and the legislation about clinical research in human subjects in each of the participating countries. The protocol was approved by the Human Research Review Committees of the involved centres ${ }^{(19)}$. Written informed consents were obtained from both adolescents and their parents.

\section{Dietary intake assessment}

Dietary intake was assessed by two non-consecutive $24 \mathrm{~h}$ recalls ${ }^{(20)}$. The $24 \mathrm{~h}$ recalls were collected with the use of a computer-based, self-administered tool, the HELENA-DIAT. This tool was adapted from a previous version developed and validated in Flemish adolescents ${ }^{(21)}$. This assessment tool is based on six meal occasions (breakfast, morning snacks, lunch, afternoon snacks, evening meal and evening snacks) referring to the previous day. Trained dietitians assisted the adolescents to complete the $24 \mathrm{~h}$ recalls when needed. Adolescents selected autonomously all the consumed foods and beverages from a standardised food list in the HELENA-DIAT $^{(22)}$. Items not available in the list could be added by the participant at any moment. Consumed foods were translated to nutrients using the German Food Code and Nutrient Data Base (Bundeslebensmittelschlüssel, BLS, version II.3.1) ${ }^{(23)}$. The Multiple Source Method was used to estimate the usual dietary intake of nutrients and foods ${ }^{(24)}$. This statistical modelling technique takes into account within-person and between-person variability and calculates usual intakes corrected for age, sex and study centre.

\section{Dietary quality index for adolescents}

A previously validated diet quality index (DQI), originally developed for preschool-aged children ${ }^{(25)}$, was adapted for use in adolescents to measure their compliance to the Flemish food-based dietary guidelines ${ }^{(26,27)}$. These Flemish food-based dietary guidelines put forward three basic principles for a healthy and balanced diet, namely dietary quality, dietary diversity and dietary equilibrium. Furthermore, the daily diet was divided into nine recommended food groups, namely (1) water, (2) bread and cereals, (3) grains and potatoes, (4) vegetables, (5) fruit, (6) milk products, (7) cheese, (8) meat, fish, eggs and substitutes and (9) fat and oils. For each of these food groups, a range of recommended daily intakes was provided. These guidelines were very similar to dietary guidelines in other countries ${ }^{(28)}$, making the index applicable to a European population. 
The technical aspects of the calculation of the dietary quality index for adolescents (DQI-A) are given in another publication $^{(29)}$. Parallel to the Flemish food-based dietary guidelines, the DQI-A consisted of three components, namely quality, diversity and equilibrium. Thus, an update version of the DQI-A composed of dietary quality, dietary diversity, dietary equilibrium and, additionally, the meal index was used.

Dietary quality. It was expressed as whether the adolescent made optimal food quality choices within a food group and was represented by a 'preference group' (e.g. fresh fruit and cereal/brown bread), a 'moderation group' (e.g. white bread) and a 'low-nutrient, energy-dense group' (e.g. soft drinks and sweet snacks).

Dietary diversity. It was expressed as the degree of variation in the diet. This score was obtained by giving points ranging from 0 to 9 when at least one serving of food of a recommended food group was consumed.

Dietary equilibrium. It was calculated from the difference between the adequacy score (which was the percentage of the minimum recommended intake for each of the main food groups) and the moderation score (which was the percentage of intake exceeding the upper level of the recommendation).

Meal index. The concept of the meal index is that a healthy diet implies also the consumption of a certain number of meals per $\mathrm{d}$. The meal index was calculated from the frequency variables 'breakfast', 'lunch' and 'dinner', representing the number of days per week that these meals were consumed.

The mean of the four components (dietary quality, diversity and equilibrium and meal index) was calculated, resulting in scores ranging from -25 to 100 . The score was calculated for each day and a mean of the daily scores was taken as the global index score of the individual.

A second index including PA (DQIPA) was employed in the present study. The PA score was obtained by the International PA Questionnaire for Adolescents (for more details on the International PA Questionnaire for Adolescents component see the following section) ${ }^{(30)}$.

\section{Physical activity}

The International PA Questionnaire for Adolescents was used to assess the PA. This questionnaire has first been developed as an instrument for adults and later adapted and validated for the HELENA population ${ }^{(30)}$. Participants were classified into low, moderate, high and vigorous PA categories according to the guidelines for data processing and analyses of the International PA Questionnaire (http://www.ipaq.ki.se/ipaq. $\mathrm{htm})$. The PA level of the adolescents was compared with the recommendation that states that adolescents should at least spend $60 \mathrm{~min}$ in moderate to vigorous physical activities per $d^{(31)}$

\section{Physical examination}

Weight was measured in underwear and without shoes with an electronic scale (Type SECA 861; SECA) to the nearest
$0.05 \mathrm{~kg}$, and height was measured barefoot plane with a telescopic height-measuring instrument (Type SECA 225; SECA) to the nearest $0 \cdot 1 \mathrm{~cm}$ in the Frankfort plane. BMI was calculated as body weight $(\mathrm{kg})$ divided by height $(\mathrm{m})$ squared $\left(\mathrm{kg} / \mathrm{m}^{2}\right)$. Skinfold thickness was measured to the nearest $0.2 \mathrm{~mm}$ in triplicate in the right side at biceps, triceps, subscapular, suprailiac, thigh and medial calf with a Holtain caliper (Holtain Limited) ${ }^{(32)}$. The sum of six skinfold thicknesses was used as an indicator of total body fat. Waist circumference was measured in triplicate at the midpoint between the lowest rib and the iliac crest with an anthropometric tape (SECA 200; SECA) ${ }^{(32)}$. Pubertal stage was assessed by a physician according to Tanner \& Whitehouse ${ }^{(33)}$. Briefly, the degree of pubertal development ranged from 1 to 5 (stages), and the classification was based on the development of the testes, scrotum and penis size in males, and on breast development and pubic hair in females. The anthropometric methods followed in the HELENA-CSS have been described in detail elsewhere $^{(34)}$

\section{Blood samples}

Detailed blood handling procedures have been described elsewhere ${ }^{(35)}$. Serum concentrations of glucose and insulin were measured after an overnight fast. The HOMA index was calculated as: (fasting insulin $(\mathrm{pmol} / \mathrm{l}) \times 6.945) \times($ fasting glucose $(\mathrm{mmol} / \mathrm{l}) / 22 \cdot 5)^{(36)}$. A quantitative insulin sensitivity check index (QUICKI) was calculated as: QUICKI $=1 /(\log$ insulin $(\mu \mathrm{IU} / \mathrm{ml})+\log$ glucose $(\mathrm{mg} / \mathrm{dl}))^{(37)}$. (To convert insulin values to $\mathrm{pmol} / \mathrm{l}$, multiply by 6.945 )

\section{Cardiorespiratory fitness}

Cardiorespiratory fitness (CRF) was measured by the progressive $20 \mathrm{~m}$ shuttle run test. This test required the subjects to run back and forth between two lines set $20 \mathrm{~m}$ apart following a running pace determined by audio signals and with an initial speed of $8.5 \mathrm{~km} / \mathrm{h}$ increasing by $0.5 \mathrm{~km} / \mathrm{h}$ every minute $(1 \mathrm{~min}$ equals one stage). The test was finished when the adolescent failed to reach the end lines concurrent with the audio signals on two consecutive occasions and the final score was computed as the number of stages completed (precision of 0.5 stages). Maximal oxygen consumption $\left(\mathrm{VO}_{2 \max }\right)$ was estimated using the formula described by Leger et $a l^{(38)}$.

\section{Statistical analysis}

Predictive Analytics Software (PASW, version 18; SPSS, Inc.) was used to perform the analyses. Statistical significance was set at $P<0 \cdot 05$. Data are presented as means and standard deviations, unless otherwise stated. To achieve normality in the residuals, BMI, insulin, CRF and the DQI-A were transformed to the natural logarithm and HOMA was raised to the power of $1 / 3$. Since an interaction effect was observed for sex on IR $(P<0 \cdot 01)$ using interaction terms (DQI $\times$ sex and DQIPA $\times$ sex) in the regression models, the analyses were thus performed separately for females and males. 
Partial correlation analyses controlling for pubertal status were performed to examine the association between dietary quality indices, markers of IR and possible confounders such as BMI and CRF. Multiple linear regression models were used to study the association of dietary quality indices (exposure variables) with the markers of IR (outcomes) after controlling for pubertal status, centre, BMI and CRF. Centre and pubertal status were entered into the models as dummy variables. The following three different models were conducted: model I included pubertal status and centre as covariates; model II included model I plus BMI; model III included model II plus CRF. Further analyses were performed using waist circumference or skinfold thickness instead of BMI. Finally, sensitivity regression analyses including total energy intake and family affluence scale as additional confounders were performed (data not shown).

\section{Results}

Table 1 shows the descriptive characteristics of the study sample. Males had significantly higher weight, height, waist circumference, glucose and CRF than females (all $P=0 \cdot 001$ ). Females had a significantly higher sum of skinfolds, insulin levels and scores for the dietary indices than males (all $P<0 \cdot 05)$. Table 2 shows partial correlations among the dietary quality indices, the markers of IR and several confounders after controlling for pubertal status. The DQI-A was directly associated with CRF in males, while the DQIPA was directly associated with CRF in both sexes.

The results of the multiple linear regression models showing the association of the dietary quality indices with the markers of IR after controlling for potential confounders for males and females are presented in Table 3. Neither the DQI-A nor the DQIPA showed any association with the markers of IR in both sexes after controlling for pubertal status, centre and
BMI (models I and II). In model III, which included model II plus CRF, the DQIPA was inversely associated with HOMA and directly with the QUICKI in females. When the analyses were repeated controlling for waist circumference or skinfold thickness instead of BMI or including additional confounders such as total energy intake (kJ) and family affluence scale (as an indicator of socio-economic status), the results did not change any more (data not shown).

\section{Discussion}

The main finding of the present study was that the DQIPA was associated with IR in European females after adjusting for several confounders including CRF. Overall, the DQIPA seems to be a more sensitive index than the DQI-A when looking for IR relationships. To our knowledge, this is the first study examining the association between several dietary quality indices (with/without PA) and IR in adolescents in a same report, which hamper comparisons with other studies. This is supported by a recent review in which authors have concluded that most of the studies examining the associations between dietary indices and health parameters are focused on the markers of adiposity as the main outcome ${ }^{(11)}$. Few studies, however, have examined the associations of dietary indices with other health parameters such as blood pressure ${ }^{(39)}$, cholesterol, TAG, glucose ${ }^{(40)}$ and the metabolic syndrome ${ }^{(41)}$.

In the descriptive analysis, the present results showed that females had significantly higher scores for the DQI-A and DQIPA than males accordingly with the overall literature that found similar trends with several diet indices, but without using PA in the index ${ }^{(11)}$. Moreover, in the initial models of adjustment (pubertal status, centre and BMI), we observed that neither the DQI-A nor the DQIPA was associated with the markers of IR in any sexes. The present results concur with those previously observed by Royo-Bordonada et al. ${ }^{(40)}$,

Table 1. Descriptive characteristics of European adolescents (Mean values and standard deviations and percentages)

\begin{tabular}{|c|c|c|c|c|c|c|c|}
\hline & \multicolumn{2}{|c|}{ All $(n$ 637) } & \multicolumn{2}{|c|}{ Males ( $n$ 290) } & \multicolumn{2}{|c|}{ Females ( $n$ 347) } & \multirow[b]{2}{*}{$P$} \\
\hline & Mean & SD & Mean & SD & Mean & SD & \\
\hline Age (years) & 14.9 & 1.3 & 14.9 & 1.3 & 14.9 & $1 \cdot 2$ & 0.803 \\
\hline Pubertal status (I/II/III/IV/V) (\%) & \multicolumn{2}{|c|}{$1 / 6 / 20 / 46 / 27$} & \multicolumn{2}{|c|}{$1 / 9 / 20 / 44 / 26$} & \multicolumn{2}{|c|}{$0 / 5 / 21 / 47 / 27$} & \\
\hline Weight $(\mathrm{kg})$ & $58 \cdot 9$ & $13 \cdot 0$ & $62 \cdot 0$ & $14 \cdot 8$ & $56 \cdot 4$ & $10 \cdot 7$ & $<0.001$ \\
\hline Height $(\mathrm{m})$ & 1.7 & 0.1 & $1 \cdot 7$ & 0.1 & 1.6 & 0.1 & $<0.001$ \\
\hline $\operatorname{BMI}\left(\mathrm{kg} / \mathrm{m}^{2}\right)^{*}$ & $21 \cdot 3$ & 3.8 & $21 \cdot 2$ & $4 \cdot 1$ & $21 \cdot 3$ & 3.5 & 0.477 \\
\hline Glucose $(\mathrm{mmol} / \mathrm{l})$ & $5 \cdot 0$ & 0.4 & $5 \cdot 1$ & 0.4 & 4.9 & 0.4 & $<0.001$ \\
\hline Sum of six skinfolds $(\mathrm{mm})$ & $89 \cdot 4$ & $41 \cdot 3$ & $73 \cdot 8$ & $39 \cdot 0$ & $102 \cdot 1$ & $38 \cdot 6$ & $<0.001$ \\
\hline Waist circumference $(\mathrm{cm})$ & $72 \cdot 2$ & $8 \cdot 2$ & 73.8 & 8.5 & $70 \cdot 9$ & $7 \cdot 7$ & $<0.001$ \\
\hline Insulin $(\mu \mathrm{IU} / \mathrm{ml})^{\star} \dagger$ & 9.8 & $7 \cdot 5$ & 9.5 & 7.9 & $10 \cdot 1$ & $7 \cdot 1$ & 0.015 \\
\hline $\mathrm{HOMA}^{*}$ & $2 \cdot 2$ & $1 \cdot 8$ & $2 \cdot 2$ & $2 \cdot 0$ & $2 \cdot 2$ & $1 \cdot 7$ & 0.173 \\
\hline QUICKI & 0.152 & 0.013 & 0.153 & 0.014 & 0.151 & 0.012 & 0.085 \\
\hline $\mathrm{CRF}(\mathrm{ml} / \mathrm{kg} \text { per } \mathrm{min})^{*}$ & $41 \cdot 3$ & 7.9 & $45 \cdot 8$ & 7.5 & $37 \cdot 1$ & 5.5 & $<0.001$ \\
\hline DQI-A* & $63 \cdot 2$ & 13.5 & 61.4 & $14 \cdot 1$ & $64 \cdot 8$ & $12 \cdot 8$ & 0.001 \\
\hline DQIPA & $69 \cdot 4$ & 11.6 & $67 \cdot 7$ & $12 \cdot 3$ & 70.7 & $10 \cdot 8$ & 0.001 \\
\hline
\end{tabular}

HOMA, homeostasis model assessment; QUICKI, quantitative insulin sensitivity check index; CRF, cardiorespiratory fitness; DQI-A, dietary quality index for adolescents; DQIPA, dietary quality index including physical activity.

* Non-transformed data are presented, but analyses were performed on log-transformed data or raised to the power of $1 / 3$. ANOVA was used for sex differences.

† To convert insulin values to pmol/l, multiply by 6.945 . 
Table 2. Partial correlations between the dietary quality indices, markers of insulin resistance and possible confounders after adjusting for pubertal status

\begin{tabular}{|c|c|c|c|c|c|}
\hline & HOMA† & Insulin† & QUICKI & BMI† & CRF† \\
\hline \multicolumn{6}{|l|}{ DQI-A† } \\
\hline Males & 0.019 & 0.010 & 0.001 & -0.052 & $0 \cdot 150^{*}$ \\
\hline Females & -0.083 & -0.077 & 0.086 & 0.101 & 0.035 \\
\hline \multicolumn{6}{|l|}{ DQIPA } \\
\hline Males & 0.012 & 0.006 & 0.006 & -0.062 & $0.260^{\star \star \star}$ \\
\hline Females & -0.101 & -0.095 & 0.103 & 0.048 & $0 \cdot 160^{\star \star \star}$ \\
\hline
\end{tabular}

HOMA, homeostasis model assessment; QUICKI, quantitative insulin sensitivity check index; CRF, cardiorespiratory fitness; DQI-A, dietary quality index for adolescents; DQIPA, dietary quality index including physical activity.

${ }^{\star} P<0.01,{ }^{\star \star \star} P<0.001$.

$\dagger$ Log-transformed data or raised to the power of $1 / 3$.

who did not find any association between a dietary variety index and glucose, as well as other health parameters. In addition, Pan \& Pratt ${ }^{(41)}$ observed a lower prevalence of the metabolic syndrome with a higher overall Healthy Eating Index among adolescents aged 12-19 years. However, based on the correlations found for the DQI-A and DQIPA with CRF in the present study, further analyses including CRF in the model were performed. Thus, the DQIPA was inversely associated with HOMA and directly with the QUICKI in females but not in males. The significant associations found only for females may be due to the higher DQIPA levels showed for this population. It is important to highlight that the present results concur with the only study of Manios et al. $^{(13)}$ including PA as part of the Healthy Lifestyle-Diet-Index in children aged 10-12 years, but they did not compare the potentially different results of including or insulin resistance in European adolescents not PA in the index. Thus, to include PA and to show the different associations of the indices with and without PA is a unique contribution of the present study.

Adolescents with a lower quality of diet and PA levels should be considered in order to prevent them from having IR. There are many factors determining the quality of the diet, but our DQIPA includes a complete spectrum of these factors and the novelty of PA information. In addition, sociodemographic characteristics depending on the country, pubertal maturation, body composition and fitness level were taken into account in the analyses. Thus, the mechanism underlying the present findings could be the lack of quality in the diet and enough PA levels that could fail to guarantee an adequate glycaemic index. This would be in accordance with studies that observed associations of the diet with glycaemic control ${ }^{(7,42,43)}$ and also of PA levels with $\mathrm{IR}^{(15,44,45)}$. It is necessary to acknowledge that the inclusion of CRF as a potential confounder could act as an intermediate variable in the pathway from the DQIPA to IR, which could introduce some bias ${ }^{(46)}$. In that case, considering that the association between the DQIPA and IR could be mediated, at least in part, by the direct effect of CRF on IR would be appropriate.

The strengths of the present study include the geographical diversity of the HELENA-CSS centres as well as the large sample of adolescents, giving a fair approximation of the overall picture of the situation in Europe. Moreover, the inclusion of PA as part of the DQI-A, the use of IR as the outcome, the adjustment for several confounders including fitness as well as a standardised and harmonised methodology are strong points from the present study. However, the present study has some limitations. First, due to its cross-sectional design, causal

Table 3. Multiple linear regression models showing the association of the dietary quality indices with the markers of

(Standardised regression coefficients $(\beta)$ and coefficients of determination $\left(R^{2}\right)$ )

\begin{tabular}{|c|c|c|c|c|c|c|c|c|c|}
\hline & \multicolumn{3}{|c|}{ Model I* } & \multicolumn{3}{|c|}{ Model II† } & \multicolumn{3}{|c|}{ Model III‡ } \\
\hline & $\beta$ & $R^{2}$ & $P$ & $\beta$ & $R^{2}$ & $P$ & $\beta$ & $R^{2}$ & $P$ \\
\hline \multicolumn{10}{|l|}{ DQI-A } \\
\hline \multicolumn{10}{|l|}{ Males } \\
\hline HOMA§ & 0.039 & 0.058 & 0.519 & 0.009 & 0.218 & 0.859 & 0.041 & 0.226 & 0.490 \\
\hline Insulin§ & 0.037 & 0.060 & 0.547 & 0.006 & 0.224 & 0.915 & 0.034 & 0.234 & 0.562 \\
\hline QUICKI & -0.024 & 0.065 & 0.691 & 0.006 & 0.214 & 0.913 & -0.016 & $0 \cdot 216$ & 0.788 \\
\hline \multicolumn{10}{|l|}{ Females } \\
\hline HOMA§ & -0.074 & 0.105 & 0.170 & -0.065 & 0.157 & 0.199 & -0.108 & 0.147 & 0.083 \\
\hline Insulin§ & -0.072 & 0.117 & 0.179 & -0.061 & 0.176 & 0.229 & -0.1 & 0.166 & 0.106 \\
\hline QUICKI & 0.079 & 0.109 & 0.139 & 0.07 & 0.157 & 0.168 & 0.113 & 0.143 & 0.071 \\
\hline \multicolumn{10}{|l|}{ DQIPA } \\
\hline \multicolumn{10}{|l|}{ Males } \\
\hline HOMA§ & 0.015 & 0.056 & 0.801 & 0.007 & 0.224 & 0.904 & 0.052 & 0.228 & 0.414 \\
\hline Insulin§ & 0.016 & 0.059 & 0.718 & 0.01 & 0.231 & 0.863 & 0.053 & 0.239 & 0.403 \\
\hline QUICKI & -0.001 & 0.065 & 0.983 & -0.008 & 0.222 & 0.884 & -0.023 & 0.219 & 0.715 \\
\hline \multicolumn{10}{|l|}{ Females } \\
\hline HOMA§ & -0.086 & 0.107 & 0.101 & -0.071 & 0.16 & 0.076 & -0.125 & 0.147 & $<0.05$ \\
\hline Insulin§ & -0.085 & 0.119 & 0.104 & -0.087 & 0.138 & 0.084 & -0.115 & 0.164 & 0.068 \\
\hline QUICKI & 0.091 & 0.111 & 0.084 & 0.095 & 0.159 & 0.064 & 0.128 & 0.142 & $<0.05$ \\
\hline
\end{tabular}

DQI-A, dietary quality index for adolescents; HOMA, homeostasis model assessment; QUICKI, quantitative insulin sensitivity check index; DQIPA, dietary quality index including physical activity.

* Included pubertal status and centre as covariates.

† Included model I plus BMI.

$\ddagger$ Included model II plus cardiorespiratory fitness.

$\S$ Log-transformed data or raised to the power of $1 / 3$. 
associations cannot be definitely established. Second, studies using questionnaire data have inherent limitations: (1) the self-reported method is subject to inaccuracy and bias, especially with behaviours such as dietary habits; (2) an individual's dietary habit can vary greatly from one day to another, limiting the reliability of a short-term recall on long-term patterns.

\section{Conclusion}

The results of the present study indicate that considering PA as part of the DQI-A is of relevance as the resulted DQIPA is inversely related to IR independently of potential confounders including CRF. Overall, these findings suggest that intervention studies aimed at preventing IR in young people should focus on increasing the quality of the diet as well as including an optimal PA level in healthy adolescents. More research on the relationships between dietary indices and different health parameters such as IR, cholesterol, the metabolic syndrome, inflammation and so on is warranted.

\section{Acknowledgements}

We gratefully acknowledge all participating children and adolescents, and their parents and teachers for their collaboration. We also acknowledge all the members involved in the fieldwork for their efforts and great enthusiasm. Additional support from the Spanish Ministry of Education (AGL2007-29784-E/ ALI; AP-2005-3827; AP-2008-03806) is acknowledged. Many thanks to Petra Pickert and Anke Carstensen for their contribution to the laboratory work. The HELENA study takes place with the financial support of the European Community Sixth RTD Framework Programme (contract no. FOOD-CT2005-007034). The present study was also supported by grants from the Spanish Ministry of Science and Innovation (JCI-2010-07055 and AP-2008-03806). The study was also supported by a grant from the Spanish Ministry of Health: Maternal, Child Health and Development Network (no. RD08/0072) (LMA).

The authors' contributions are as follows: D. J.-P., M. A. S. and L. A. M. contributed to the concept and design of the study; D. J.-P., M. A. S., G. P., J. R. R., C. B., C. L., L. B., M. P., Y. M., O. A., J. D., A. K., K. W., D. M. and L. A. M. contributed to the conduct of the study; D. J.-P., M. A. S., M. C.-G., I. H. and L. A. M. contributed to the analysis and interpretation of the data; D. J.-P., M. A. S., I. H., M. C.-G. and L. A. M. contributed to the drafting of the manuscript; D. J.-P., M. A. S., G. P., J. R. R., C. B., C. L., L. B., M. P., Y. M., O. A., J. D., A. K., K. W., D. M. and L. A. M. critically reviewed the manuscript. All authors read the manuscript and had important critical input before the final approval.

The authors have no conflicts of interest.

\section{References}

1. Levy-Marchal C, Arslanian S, Cutfield W, et al. (2010) Insulin resistance in children: consensus, perspective, and future directions. J Clin Endocrinol Metab 95, 5189-5198.
2. Misra A, Khurana L, Isharwal S, et al. (2009) South Asian diets and insulin resistance. Br J Nutr 101, 465-473.

3. Andersen LB, Harro M, Sardinha LB, et al. (2006) Physical activity and clustered cardiovascular risk in children: a cross-sectional study (The European Youth Heart Study). Lancet 368, 299-304.

4. Brambilla P, Pozzobon G \& Pietrobelli A (2011) Physical activity as the main therapeutic tool for metabolic syndrome in childhood. Int J Obes (Lond) 35, 16-28.

5. Guinhouya BC, Samouda H, Zitouni D, et al. (2011) Evidence of the influence of physical activity on the metabolic syndrome and/or on insulin resistance in pediatric populations: a systematic review. Int J Pediatr Obes $\mathbf{6}$, 361-388.

6. Ambrosini GL, Huang RC, Mori TA, et al. (2010) Dietary patterns and markers for the metabolic syndrome in Australian adolescents. Nutr Metab Cardiovasc Dis 20, 274-283.

7. Bremer AA, Auinger P \& Byrd RS (2009) Relationship between insulin resistance-associated metabolic parameters and anthropometric measurements with sugar-sweetened beverage intake and physical activity levels in US adolescents: findings from the 1999-2004 National Health and Nutrition Examination Survey. Arch Pediatr Adolesc Med 163, 328-335.

8. Harrington S (2008) The role of sugar-sweetened beverage consumption in adolescent obesity: a review of the literature. J Sch Nurs 24, 3-12.

9. Isharwal S, Arya S, Misra A, et al. (2008) Dietary nutrients and insulin resistance in urban Asian Indian adolescents and young adults. Ann Nutr Metab 52, 145-151.

10. Sese MA, Jimenez-Pavon D, Gilbert CC, et al. (2012) Eating behaviour, insulin resistance and cluster of metabolic risk factors in European adolescents. The HELENA Study. Appetite 59, 140-147.

11. Lazarou C \& Newby PK (2011) Use of dietary indexes among children in developed countries. Adv Nutr 2, 295-303.

12. Linardakis M, Sarri K, Pateraki MS, et al. (2008) Sugar-added beverages consumption among kindergarten children of Crete: effects on nutritional status and risk of obesity. $B M C$ Public Health 8, 279.

13. Manios Y, Kourlaba G, Grammatikaki E, et al. (2010) Development of a lifestyle-diet quality index for primary schoolchildren and its relation to insulin resistance: the Healthy Lifestyle-Diet Index. Eur J Clin Nutr 64, 1399-1406.

14. Ekelund U, Luan J, Sherar LB, et al. (2012) Moderate to vigorous physical activity and sedentary time and cardiometabolic risk factors in children and adolescents. JAMA $\mathbf{3 0 7}$, $704-712$.

15. Jiménez-Pavón D, Ruiz JR, Ortega FB, et al. (2013) Physical activity and markers of insulin resistance in adolescents; role of cardiorespiratory fitness levels. The HELENA study. Pediatr Diabetes (epublication ahead of print version 10 January 2013).

16. Bhatia V (2004) IAP National Task Force for Childhood Prevention of Adult Diseases: insulin resistance and type 2 diabetes mellitus in childhood. Indian Pediatr 41, 443-457.

17. Moreno LA, De Henauw S, Gonzalez-Gross M, et al. (2008) Design and implementation of the Healthy Lifestyle in Europe by Nutrition in Adolescence Cross-Sectional Study. Int J Obes (Lond) 32, Suppl. 5, S4-S11.

18. Moreno LA, Gonzalez-Gross M, Kersting M, et al. (2008) Assessing, understanding and modifying nutritional status, eating habits and physical activity in European adolescents: the HELENA (Healthy Lifestyle in Europe by Nutrition in Adolescence) Study. Public Health Nutr 11, 288-299. 
19. Beghin L, Castera M, Manios Y, et al. (2008) Quality assurance of ethical issues and regulatory aspects relating to good clinical practices in the HELENA Cross-Sectional Study. Int J Obes (Lond) 32, Suppl. 5, S12-S18.

20. Biro G, Hulshof KF, Ovesen L, et al. (2002) Selection of methodology to assess food intake. Eur J Clin Nutr 56, Suppl. 2, S25-S32.

21. Vereecken CA, Covents M, Matthys C, et al. (2005) Young adolescents' nutrition assessment on computer (YANA-C). Eur J Clin Nutr 59, 658-667.

22. Vereecken CA, Covents M, Sichert-Hellert W, et al. (2008) Development and evaluation of a self-administered computerized 24-h dietary recall method for adolescents in Europe. Int J Obes (Lond) 32, Suppl. 5, S26-S34.

23. Dehne LI, Klemm C, Henseler G, et al. (1999) The German Food Code and Nutrient Data Base (BLS II.2). Eur J Epidemiol 15, 355-359.

24. Haubrock J, Hartigg U, Souverein O, et al. (2010) An improved statistical tool for estimating usual intake distributions: the Multiple Source Method (MSM). Arch Public Health 68, 14-15.

25. Huybrechts I, Vereecken C, De Bacquer D, et al. (2010) Reproducibility and validity of a diet quality index for children assessed using a FFQ. Br J Nutr 104, 135-144.

26. Vigez (2012) The Active Food Guide Pyramid. Belgium: Het Vlaams Instituut voor Gezondheidspromotie en Ziektepreventie (VIGeZ). http://www.vigez.be/uploads/documenten bank/dfe08f69103a429814928a6b66213d78.pdf

27. Vigez (2012) De voedingsdriehoek: een praktische voedingsgids (The Active Food Pyramid: A Practical Guide to Diet and Physical Activity). Belgium: Het Vlaams Instituut voor Gezondheidspromotie en Ziektepreventie (VIGeZ). http://www.vigez.be/uploads/documentenbank/5a7c436f94 286eaa39e16c65b1a55182.pdf

28. European Food Information Council (EUFIC) (2011) FoodBased Dietary Guidelines - are we are on the right track? http://www.eufic.org/article/en/nutrition/understandingfood/ artid/Food-Based-Dietry-Guidelines-on-right-track/

29. Vyncke K, Cruz Fernandez E, Fajó-Pascual M, et al. (2013) Validation of the Diet Quality Index for Adolescents (DQI-A) by comparison with biomarkers, nutrient and food intakes: the HELENA study. Br J Nutr 109, 2067-2078.

30. Hagstromer M, Bergman P, De Bourdeaudhuij I, et al. (2008) Concurrent validity of a modified version of the International Physical Activity Questionnaire (IPAQ-A) in European adolescents: The HELENA Study. Int J Obes (Lond) 32, Suppl. 5, S42-S48.

31. Strong WB, Malina RM, Blimkie CJ, et al. (2005) Evidence based physical activity for school-age youth. J Pediatr 146, $732-737$.

32. Lohman TG, Roche AF \& Martorell R (1988) Anthropometric Standardization Reference Manual. Champaign, IL: Human Kinetics Books.
33. Tanner JM \& Whitehouse RH (1976) Clinical longitudinal standards for height, weight, height velocity, weight velocity, and stages of puberty. Arch Dis Child 51, 170-179.

34. Nagy E, Vicente-Rodriguez G, Manios Y, et al. (2008) Harmonization process and reliability assessment of anthropometric measurements in a multicenter study in adolescents. Int $J$ Obes (Lond) 32, Suppl. 5, S58-S65.

35. Gonzalez-Gross M, Breidenassel C, Gomez-Martinez S, et al. (2008) Sampling and processing of fresh blood samples within a European multicenter nutritional study: evaluation of biomarker stability during transport and storage. Int $J$ Obes (London) 32, Suppl. 5, S66-S75.

36. Matthews DR, Hosker JP, Rudenski AS, et al. (1985) Homeostasis model assessment: insulin resistance and beta-cell function from fasting plasma glucose and insulin concentrations in man. Diabetologia 28, 412-419.

37. Katz A, Nambi SS, Mather K, et al. (2000) Quantitative insulin sensitivity check index: a simple, accurate method for assessing insulin sensitivity in humans. J Clin Endocrinol Metab 85, 2402-2410.

38. Leger L, Lambert J, Goulet A, et al. (1984) Aerobic capacity of 6 to 17-year-old Quebecois - 20 meter shuttle run test with 1 min stages. Can J Appl Sport Sci 9, 64-69.

39. Lazarou C, Panagiotakos DB \& Matalas AL (2009) Foods E-KINDEX: a dietary index associated with reduced blood pressure levels among young children: the CYKIDS study. J Am Diet Assoc 109, 1070-1075.

40. Royo-Bordonada MA, Gorgojo L, Ortega H, et al. (2003) Greater dietary variety is associated with better biochemical nutritional status in Spanish children: the Four Provinces Study. Nutr Metab Cardiovasc Dis 13, 357-364.

41. Pan Y \& Pratt CA (2008) Metabolic syndrome and its association with diet and physical activity in US adolescents. $J \mathrm{Am}$ Diet Assoc 108, 276-286 (discussion 286).

42. Overby NC, Margeirsdottir HD, Brunborg C, et al. (2007) The influence of dietary intake and meal pattern on blood glucose control in children and adolescents using intensive insulin treatment. Diabetologia 50, 2044-2051.

43. Perichart-Perera O, Balas-Nakash M, Rodriguez-Cano A, et al. (2010) Correlates of dietary energy sources with cardiovascular disease risk markers in Mexican school-age children. J Am Diet Assoc 110, 253-260.

44. Ekelund U, Brage S, Griffin SJ, et al. (2009) Objectively measured moderate- and vigorous-intensity physical activity but not sedentary time predicts insulin resistance in high-risk individuals. Diabetes Care 32, 1081-1086.

45. Thomas AS, Greene LF, Ard JD, et al. (2009) Physical activity may facilitate diabetes prevention in adolescents. Diabetes Care 32, 9-13.

46. Schisterman EF, Cole SR \& Platt RW (2009) Over adjustment bias and unnecessary adjustment in epidemiologic studies. Epidemiology 20, 488-495. 